\title{
La memoria y la forma política: una lectura de Carl Schmitt sobre la soberanía y el estado de excepción*
}

\author{
Memory and Political Form: A Reading by Carl Schmitt about Sovereignty and State of Emergency
}

\author{
Luis Felipe Vega Diaz ${ }^{\mathrm{a}}$ \\ Pontificia Universidad Javeriana, Colombia \\ Ifvega@javeriana.edu.co \\ ORCID: http://orcid.org/0000-0001-6112-8217 \\ Dora Inés Avella de Martínez \\ Universidad Militar Nueva Granada, Colombia \\ ORCID: http://orcid.org/0000-0001-7101-2138
}

DOI: https://doi.org/10.11144/Javeriana.papo23-2.mfpl Redalyc: http://www.redalyc.org/articulo.oa?id=77757839008

Fecha de recepción: 18 Octubre 2017

Fecha de aprobación: 01 Mayo 2018

Fecha de publicación: 18 Diciembre 2018

\section{Resumen:}

El objetivo de este artículo es hacer una presentación sobre la relación existente entre la forma política de la soberanía y la forma de la memoria como gobierno en el marco de la posguerra de la Segunda Guerra Mundial, con respecto al desarrollo de la democracia representativa liberal en las ideas de Carl Schmitt. En efecto, las discusiones en torno a la influencia de la memoria colectiva en la esfera de la toma de decisiones políticas suponen el resurgimiento de los sentimientos nacionales, a partir de la comprensión de las amenazas globales, por lo que estos sentimientos logran agregarse bajo la figura de un "dictador benévolo" [1], en cuanto decisor sin mediación institucional, y particularmente del "estado de excepción” (Ausnahmezustand) como forma política más que como forma jurídica. Así, el resurgimiento de los nacionalismos y de liderazgos políticos rebasa las formas del populismo por sus componentes teológicos en la composición suprahistórica de los caudillos como decisores sobre la vida de la población. Aunado a esto, la fuerza del nacionalismo como factor de catalización de los procesos políticos internos y de política exterior del concepto binario amigo-enemigo desplaza la comprensión de la política al reencuentro con la memoria de la guerra, a través de la que Carl Schmitt avizoraba, desde los procesos de Núremberg de 1948, una suerte de guerra civil mundial, debido a la imagen de triunfo de una especie de democracia liberal anglosajona.

Palabras clave: Carl Schmitt, memoria histórica, verdad, conflicto.

\section{Abstract:}

This article aims to present an overview on the relationship between the political form of sovereignty and the memory form of a government in the WWII post-war framework as described by Carl Schmitt. In fact, the discussions on how the collective memory influences the sphere of the political decision-making suppose the resurgence of the national feelings based on the understanding of the global threats. Thus, such feelings are aggregated in the form of a "benevolent dictator" who makes decisions without any institutional mediation and, particularly, using the "state of emergency" (Ausnahmezustand) as a political form rather than a legal form. This way, the resurgence of nationalisms and political leadership overtakes the different populism forms thanks to the theological components in the suprahistorical creation of the caudillos, as decision-makers on the population life. Additionally, the nationalism force as a catalyzing factor for both domestic political processes and foreign policies under the concept friend-enemy moves the understanding of the politics towards a reencounter with the war memory, by means of what Carl Schmitt sensed since the 1948 Nuremberg trials, a kind of civil world war due to the triumphant image of a sort of Anglo-Saxon liberal democracy.

Keywords: Carl Schmitt, historical memory, truth, conflict.

\section{El asunto de la memoria y la justicia en la posguerra}

[...] Todo me ha atravesado. Conozco los muchos estilos del terror, el de arriba, el de abajo, el terrestre y el aéreo. El legal y el sin ley, el pardo, el rojo, el terror variopinto, y, el peor, en que nadie se atrevería a hablar. Sí. Todos los conozco y, de sus garras, sé. Conozco los coros aullantes, los altavoces falsarios, las listas negras, con nombres y más nombres, y los ficheros de los perseguidores. ¿Qué debo, pues, cantar? ¿El himno de Placebo, ¿Me dormiré en la paz de las plantas y animales?, ¿Me

Notas de autor:

a Autor de correspondencia. Correo electrónico: Ifvega@javeriana.edu.co 
elevaré pánicamente en el círculo de los paniscos?, ¿Beato, con giróvago mosquito? Tres veces, me he encontrado en el vientre del pez. Tres veces, vi la muerte en ojos del verdugo. Dos poetas sibilinos prestáronme custodia. (Schmitt, 2010)

\section{“Gesang des Sechzigjährigen”, Carl Schmitt}

En el 2007 se cumplieron sesenta años de los interrogatorios de Núremberg hechos a Carl Schmitt, los cuales fueron publicados en la década de los ochenta por la revista Telos ${ }^{[2]}$. Dichos interrogatorios estuvieron a cargo del fiscal Robert M. W. Kempner. La experiencia más significativa de este fiscal fue su presencia como observador en el proceso en contra de Soghomon Tehilirian, genocida armenio quien mató al gran visir Talaat Pasha el 15 de marzo de $1921^{[3]}$. Resulta interesante que Kempner, de familia judía, se convirtiera en un prestigioso abogado durante la segunda década de siglo XX en Berlín ${ }^{[4]}$. Posteriormente, le fue revocada la ciudadanía alemana en 1935 y se vio obligado a emigrar a los Estados Unidos.

El proceso contra Schmitt a cargo de Kempner tendría una connotación importante en los juicios de la posguerra, en cuanto se pretendía encontrar a los determinadores ideológicos del nacionalsocialismo. Lo anterior porque el mismo interrogador, habiéndose presentado como exiliado, venía a acusar a sus perseguidores (Bendersky, 1983, p. 62). Adicionalmente, el factor más importante que se desea resaltar aquí es el antecedente político del proceso jurídico: la acusación se haría bajo la influencia del derecho positivo alemán entronizado en la fallida Constitución de Weimar, a su vez con el lente interpretativo del contractualismo de uso conceptual de la democracia anglosajona, entendiéndolo como una radicalización de la implementación de la justicia, como se mostrará en lo que sigue. Sin embargo, es vital considerar la correspondencia dirigida por Jakob Taubens a Carl Schmitt en 1986, en la que se plantea el tema central no resuelto de la memoria como forma jurídica que está en la base de las causas de la guerra:

Just als Erzjude weiß ich zu zögern, den Stab zu brechen. Weil in all dem unaussprechlichen Grauen wir vor einem bewahrt blieben. Wir hatten keine Wahl: Hitler hat uns zum absoluten Feind erkoren. Wo aber keine Wahl besteht, auch kein Urteil, schon gar nicht über Andere. ${ }^{[5]}$

Luego de que se encontrara una nueva documentación histórica de archivo sobre el proceso de Carl Schmitt en Núremberg, llama la atención especialmente la transcripción de un "cuarto" interrogatorio del 11 de abril de 1947, el cual aparecerá en la mencionada revista Telos en el verano de $1987^{\text {[6] }}$. Se puede decir que más que hacer claridad sobre el tiempo de su encierro desde 1945, en el que escribirá una obra fundamental para la comprensión política de la posguerra, titulada "Ex captivitate Salus" ${ }^{[7]}$, dicho interrogatorio es determinante para entender no solo el pasado de Schmitt y su afinidad con el nacionalsocialismo, sino particularmente la quintaesencia que marca un punto de anclaje para su comprensión política respecto al problema de la soberanía - anótese que dicha comprensión se hace evidente solo al hacer la memoria en términos judiciales de la guerra-, sobre todo en cuanto define el plano de "presente" en el que se despliegan un conjunto de relaciones de fuerza que redefinen la relación amigo-enemigo, tan determinante en Schmitt. Heinrich Meier (1995), en su trabajo sobre las conversaciones ocultas entre Leo Strauss y Carl Schmitt, logra aclarar mucho mejor lo que afirmamos: "The enemy defines himself as enemy by means of the attack, the will to Ward him off is 'fully self-evident”' (p. 19).

En efecto, dentro del mencionado proceso para los investigadores no se había satisfecho explicativamente la relación que existió entre Carl Schmitt y el nacionalsocialismo, en especial su rol ideológico en aquel movimiento. El interés estuvo demarcado en especial por el general Lucius Clay y grupos de intelectuales afines a un liberalismo positivo, tanto americanos como alemanes, quienes veían en Schmitt a uno de los grandes responsables políticos del desarrollo ideológico del nacionalsocialismo en Alemania. Es importante anotar que luego de la primera publicación de este interrogatorio, Kempner afirmó en una entrevista (Bendersky, 1987, 101) en 1973 que la presión respecto a aquel juicio provenía del gobierno militar americano 
en Berlín. Así, a partir de las intenciones del general Clay se intentó imputar a Schmitt como criminal de guerra, tipificando su conducta como gran determinador del holocausto debido a su teoría de la decisión del soberano en el estado de excepción.

Según lo publicado por Telos en 2007, fue Karl Lowenstein quien firmó el primer memorando para el arresto de Schmitt en 1946, lo que supone que este último no había sido detenido en 1945, y que de suyo ya se presentaba una inconsistencia con las versiones oficiales sobre su periodo de encierro. Lowenstein no era desconocido por Schmitt, ya en 1925 había discutido "la crítica contra el parlamentarismo", llamándola ingeniosa teatralización. Del mismo modo, centró otra de sus principales críticas en la interpretación que hacía este del artículo 76 de la constitución de Weimar, referida a la reforma de la Constitución por vía parlamentaria ${ }^{[8]}$. El centro de esta crítica estuvo fundado en que la noción formalista de la igualdad mecánica antes de la ley había permitido la subversión o la torsión de la Constitución de Weimar, y con ello el principio de una dictadura con las terribles consecuencias que se desencadenarían a partir de 1939. Es plausible afirmar que Lowenstein concibe como más que peligrosa la distinción hecha por Schmitt entre liberalismo y democracia, ya que esta permite la violación de los derechos humanos inalienables e individuales hecha por fuerzas populares que se autodeterminan como democráticas populares (Bendersky, 2007, p. 271). Así mismo, las contribuciones que empieza a hacer Schmitt en 1930 respecto al papel de la Constitución y un defensor de esta, le permiten a Lowenstein calificarle como un oportunista y la principal influencia en una suerte de teoría del derecho constitucional que transforma los marcos legales y permite tejer un manto de legitimidad del régimen nazi.

Sin embargo, las críticas a Schmitt no solo proceden de las posturas intelectuales liberales. El sector radical del nacionalsocialismo, a través de Otto Koellreutter, conocido jurista nacionalsocialista, en su correspondencia con Schmitt critica a este último por sus posiciones débiles, en especial sus proposiciones generales sobre el fundamento de la Constitución. Ello, principalmente, porque a su parecer Schmitt refleja la imagen de un Estado constructivista y no un Estado popular como debía entenderse el proceso de formación del III Reich en su sentido de presente absoluto. Koellreutter lleva adelante una persecución contra Schmitt desde el corazón del nacionalsocialismo alemán, fundada en aquello que denomina neohegelianismo conservador, es decir, entiende que Schmitt en su teoría política no recurre a los argumentos raciales ni contribuye con nada sustancial al nacionalsocialismo (Meier, 2008, p. 184). Así, en tanto Lowenstein con el argumento de "democracia militante" trata de hallar en Schmitt el fundamento ideológico del nacionalsocialismo, y ve en este el origen ideológico que constituye la legitimidad de un régimen totalitario que elimina las libertades de los individuos y sus derechos por medio de la imagen de una democracia de fuerzas populares, por otro lado Koellreutter acusa a Schmitt de neohegeliano conservador que no toma las bases de la raza para fortalecer el papel del Estado popular alemán que se hace visible y realizable jurídicamente en el III Reich alemán.

\section{El defensor de la Constitución como figura histórica: el principio de identidad en contra de la representación política ¿ Un principio de la dictadura?}

[...] Perhaps I may also say, in addition, that I have also derived from your later works, especially the "Diktatur" a confirmation of my modes of research in the philosophy of art from yours in the philosophy of the state. If the reading of my book allows this feeling to emerge in an intelligible fashion, then the purpose of my sending it to you will be achieved. With my expression of special admiration, your very humble. Walter Benjamin ${ }^{[9]}$

En agosto de 1945 Lowenstein se reunirá con el coronel McLendon para poder revisar de primera mano documentos concernientes al caso de Schmitt, y el 21 de septiembre escribirá su famosa lista de objetos importantes para ser incluidos como elementos acusatorios y probatorios en dicho proceso. Durante este mismo periodo, la correspondencia de Schmitt y su esposa deja entrever lo que realmente percibía el 
importante jurista alemán en torno a dichos procesos políticos, o mejor, el haber caído en manos de los liberales demócratas. Schmitt, en las cartas a su esposa Duschka, afirma: "El Leviatán en cuyas garras estoy atrapado, es una bestia fuerte e inmisericorde" (citado en Bendersky, 2007, p. 257-283) ${ }^{[10]}$.

El 4 de octubre de 1945 Lowenstein y el capitán Fearnside revisaron la biblioteca de Schmitt, sus casi 5000 volúmenes, colección que encerraba la más completa bibliografía sobre derecho y política alemana. El objeto de aquella visita obedecía a dos propósitos: por una parte, proveer de una fuerte biblioteca al nuevo gobierno, debido a la devastación de las librerías, y por otro, encontrar "instrumentos de confrontación" en caso de que Schmitt negara su pasado nazi ${ }^{[11]}$. La principal pieza de evidencia fue el artículo de Schmitt, publicado en 1940, titulado "Der Führer schütz das Recht" ${ }^{[12] ~(l o ~ q u e ~ t r a d u c e ~ " e l ~ r o l ~ d e l ~ F u ̈ h r e r ~ c o m o ~ d e f e n s o r ~ d e l ~}$ derecho"). Los principios esgrimidos en dicha conferencia pronunciada en Leipzig iban a ser posteriormente consignados en su libro publicado en 1931 con el título de La defensa de la Constitución, donde asegura que la garantía constitucional no puede ser defendida por la misma Constitución - en clara contraposición a Kelsen y Hugo Preuß-, sino solo por la figura de "un defensor".

Schmitt, al iniciar este texto, asegura que la demanda de un protector de la constitución es, en la mayoría de los casos, indicio de situaciones críticas para la Constitución, acudiendo a las figuras históricas de este tipo de defensor como corpus de la tradición de la teoría jurídica (Schmitt, 1983, pp. 36 y ss.). Esta misma proposición aparece después de la muerte de Cromwell en 1658, posteriormente en Harrington, seguida de la Constitución napoleónica del año VIII de la Revolución (1799), y en las constituciones alemanas de Baviera de 1818 y Baja Sajonia de 1831. Puede centrarse en cuatro puntos esenciales: (1) el juramento del rey, los servidores del Estado y los ciudadanos a la Constitución; (2) el derecho a formular quejas por infracciones a la Constitución; (3) el derecho de los estamentos a presentar acusaciones por este mismo hecho; (4) sobre las condiciones para llevar a cabo una reforma a la Constitución (Schmitt, 1983, p. 52).

De ello surge la imagen desde la Constitución de Weimar del Tribunal Constitucional como defensor de la Constitución, la cual Schmitt controvertiría en la última parte del citado libro con su teoría del poder neutral. En esta, es el presidente del Reich quien debe ejercer tal defensa de la Constitución, ello con el fin de evitar discusiones legalistas, ya que incluso los mismos jueces no se escapan en independencia al interés político de los partidos. En sus palabras:

[...] mejor, sería recordar, en primer término, el sentido positivo de la constitución de Weimar y de su sistema de preceptos. Según el contenido efectivo de la Constitución de Weimar existe ya un protector de la Constitución, a saber: El Presidente del Reich. (Schmitt, 1983, p. 186)

Lowenstein retoma sus acusaciones asegurando que Schmitt, incluso en 1936, después del ataque hecho en su contra por las SS, continuaba publicando en sus obras una defensa del totalitarismo y del control del sistema europeo por la Alemania nacionalsocialista. Esto último le permitiría argumentar a Lowenstein la necesidad de la permanencia de Schmitt en presidio y mantener su estatus de criminal de guerra. Sin embargo, cabe la pregunta: ¿ por qué existe una fascinación en Schmitt por el defensor de la Constitución, quien en su acto de decisión determina el estado de excepción? En síntesis, ¿a través de la acusación de Lowenstein, se puede percibir que no existe ninguna pretensión moral en el acto del soberano al decidir, y que en ello hay un acto político per se que contradice toda tradición que funda la decisión del soberano en su imagen como representación de los individuos a él sujetos?

El centro de esta acusación abre la puerta a la comprensión de este asunto. La aparente fascinación de Carl Schmitt por la dictadura ${ }^{[13]}$ es manifiesta en dos de sus obras: Die Diktatur y Die Verfassunglehre. En ambas, asocia el sentimiento afecto al totalitarismo a su comprensión del catolicismo y en particular la complexio oppositorum ${ }^{[14]}$, además de su afección particular por Donoso Cortés ${ }^{[15]}$. Para Schmitt, la imagen del "defensor de la Constitución" supera la figura de Hitler y de cualquier tipo de militancia en el nacionalsocialismo, a pesar de que esté centrada en su figura. Ello muestra que la figura del defensor no está restringida a Hitler. En efecto, su concepto de defensa de la Constitución supone la base de la 
consolidación del Estado como un estatus colectivo, y por ende lo político mismo que, expresado en la forma misma constitucional, define la necesidad de un defensor para sí misma. En ese sentido, "el defensor de la Constitución" es el protector de ese estatus colectivo que dista mucho de ser un pacto de voluntades. Así, la figura de la centralización del poder en la forma de soberanía no supone de suyo una agregación de voluntades representadas, y por ende el totalitarismo resulta ser un concepto bastante simplista para definir el problema de la soberanía y su relación en el marco de la decisión.

\section{Breve genealogía del nacionalismo alemán: superficie de contexto de la memoria en Carl Schmitt}

La idea de una imagen de soberanía que más allá de ser una simple centralidad es el basamento político que supera toda condición histórica, tiene antecedentes en la tradición alemana en las imágenes del nacionalismo de finales de siglo XIX, particularmente en la obra de Treitschke ${ }^{[16]}$ titulada Die Politik. En esta, el autor establece una condición moral que logra materializarse en un factor decisivo de la forma del Estado. Así, el nacionalismo alemán de finales de siglo XIX como fuente de referencia histórica del trabajo de Schmitt tiene una premisa capital: un Estado débil es de suyo una contradicción. De esta manera, la tradición del nacionalismo alemán de siglo XIX, a diferencia de otros discursos nacionales, al hacer mención del Estado y de su fortaleza, evidencia que su supervivencia reside en la capacidad material y formal de la decisión y no en un soberano como objeto de la representación de los individuos que escapan de la condición ahistórica de violencia por naturaleza (Schmitt, 1996, p. 31). Esto, puesto en una proposición más comprensible, implica que la figura del soberano identifica este estatus colectivo o modo de ser de un pueblo.

En su crítica a Treitschke, Durkheim muestra bien en su ensayo titulado "Deutschland über alles" [17] , esta preocupación por el nacionalismo alemán. En palabras citadas por Durkheim del mismo Treitschke: "está en la esencia misma del Estado no tener ninguna fuerza por encima de él". Más adelante el mismo autor dirá: "fuera del Estado la humanidad no puede respirar". Así, el concepto de totalidad se encontraría en la naturaleza del Estado como fuerza moral y expresión material de la soberanía (Durkheim, 1989, p. 206). Pero ello, de antemano, no supone un concepto de totalitarismo, a pesar de que los procesos desde 1936 en Alemania llevaran al país a un modelo totalitarista. Es necesario afirmar que a finales del siglo XIX un proceso así es imposible de pensar, por la influencia de la Constitución de $1849^{[18]}$ y la respuesta de Prusia liderada por Federico Guillermo. Este proceso lo que determinó en relación con la soberanía fue su centralidad y molaridad, y con ello la incapacidad tanto de una república como de una de una revolución liberal. En palabras de Donoso Cortés sobre los peligros de la Constitución de Frankfurt:

Nunca atravesó Europa otra crisis más formidable. Espero aun, sin embargo, que la Asamblea de Fráncfort no se atreverá a dar el paso decisivo; más si tuviese tal atrevimiento, me complazco en creer que el rey de Prusia rechazaría con honor la funesta corona que se le quiere ofrecer. (Donoso, 1946, p. 666)

Así, el debate entre los intentos de un republicanismo alemán enfrentados al absolutismo mismo del monarca diferencia los términos tanto de absolutismo como de totalitarismo. El primero reside en la fuerza moral proveniente del soberano en la figura del emperador y su condición de sacralidad como base de su legitimidad, en tanto que el segundo se vale del sistema político para buscar a través de una forma de partido único, una centralidad de poder en un líder político como forma de legitimidad, por medio de mecanismos plebiscitarios para instituir un régimen (Kolluta, 2008, p. 419).

Para entender esto es determinante comprender la figura de Bismarck en dicho proceso a través de su política de alianzas en términos de la realpolitik [19] . Para Bismarck, el punto central residió en evitar fundamentalmente cualquier tipo de gobierno liberal, estableciendo una suerte de interpretación del discurso sobre la nación a través de una suerte de romanticismo como colofón de la centuria que inauguraba a Alemania 
como el eje central de la política europea (Schulze Schneider, 1996, p. 31). Alemania había logrado hacer síntesis bajo el concepto de Kulturkampf de una dinámica particular de política interna. En efecto, este romanticismo que aparecía de la primera década de siglo XIX tiene sobre la comprensión de la realpolitik de Bismarck una condición determinante: la eliminación del enemigo interno - en este caso, la forma liberal infecciosa que había sobrevivido al 48 y pretendía reaparecer bajo la amenaza de crisis del Reich y por ende de su principio identitario el káiser-.

Ahora bien, ¿cuáles son los dos discursos que reaparecen en este horizonte? Por una parte, el discurso sobre una naturaleza alemana por antonomasia usado por Fichte en los discursos sobre la nación alemana:

Que hablo a alemanes por antonomasia de alemanes por antonomasia ${ }^{[20]}$, no reconociendo, sino desechando totalmente y desdeñando todas las diferencia disgregadoras que han dado lugar desde siglos a acontecimientos nefastos para una nación. Por cierto, ante mis ojos, son ustedes, distinguida asamblea, los representantes primeros y directos que me actualizan las queridas características fundamentales nacionales y el núcleo visible en que se enciende la llama de mi discurso, pero mi espíritu reúne en torno a sí a la clase culta de toda la nación alemana desde todos los países sobre los que se ha extendido. (Fichte, 1994, pp. 50-51)

En este orden de ideas, la nación alemana no se convierte en un espíritu hegeliano, sino en un sentido propio del historicismo propio del romanticismo alemán de siglo XIX, plenamente manifiesto en el concepto de Kulturkampf. La nación no es fruto de un proceso dialéctico, es una suerte de esencialismo histórico que expresa una manera de ser colectiva. Por otra parte, reaparece la interpretación de Clausewitz, en la cual se sostiene que el principio operativo que enmarca la construcción de la nación es la aparición de un enemigo común para Prusia y para todos los alemanes, que en la primera década del siglo XIX no podía ser otro que Napoleón. El asunto esencial es cómo Napoleón se convirtió en un enemigo de prusianos y alemanes que terminó construyendo sobre esta enemistad la base en la cual posteriormente Bismarck fundará el nacimiento del Primer Reich (Schmitt, 1969, pp. 18 y ss.). A este respecto, son tres los factores que anota Carl Schmitt: (1) el rey de Prusia notaba que su legitimidad dinástica estaba amenazada por los planes de armamento popular apetecidos por los reformadores militares. En efecto, los reformadores del ejército pensaban en el potencial de guerra que se encontraba en las dos legitimidades opuestas, y esperaban poder cambiarlo. Ante un enemigo como Napoleón el riesgo era evidente; (2) en el núcleo del problema está la enemistad prusiana contra Napoleón, emperador de los franceses, que surge entonces. El memorándum-confesión de Clausewitz de 1812 es en su totalidad un documento inquietante de una enemistad profunda y desesperada. En realidad, los alemanes eran frente a Napoleón un pueblo dividido; (3) en 1812 se convirtió, efectivamente, en enemigo abierto de Napoleón. ¿De dónde, pues, venía la enemistad de los alemanes? Clausewitz opuso una contestación dura y sobria, se puede decir prusiana, a las intenciones pacíficas de Napoleón. Se encuentra en el segundo libro De la guerra, capítulo 5, titulado "Carácter de la defensa estratégica": "El conquistador es siempre pacífico (como Bonaparte solía afirmarlo siempre), le gustaría entrar tranquilamente en nuestro Estado; pero para que esto no le sea posible tenemos que querer la guerra, y prepararla” (Schmitt, 1969, p. 19).

Así, Bismarck, a partir de estos dos factores, uno discursivo y otro operativo en la forma del enemigo, unifica la forma administrativa de un concepto o espíritu de nación histórico y románticamente una suerte de naturalismo preexistente (Nationswessen) o naturaleza de la nación. En 1890 llegó al poder Guillermo II y destituyó a Bismarck, lo que produjo un importante viraje en la política alemana. De la Realpolitik de Bismarck, que aseguraba el equilibrio de fuerzas y una paz duradera en Europa, se pasaba a la Weltpolitik, una política abanderada por Guillermo II y que se caracterizaba por ser mucho más ambiciosa y agresiva al romper el equilibrio internacional, lo que iba a generar mayor tensión. Estos cambios se iban a plasmar en el alejamiento de Rusia como aliado de la órbita alemana, el fin del aislamiento de Francia y el desarrollo de unas ambiciones coloniales por parte de Alemania que iban a chocar con Gran Bretaña (Waller, 1999, p. 93). El punto de atención sobre la radicalización de Guillermo II está en que la lucha del nacionalismo adquiere una condición de supervivencia. Esto es, la nación siempre está en peligro de muerte, su naturaleza es la supervivencia, y por ende lo que está en juego es la existencia colectiva y su forma política. 
Este debate se desarrollará nuevamente en el centro mismo de la revolución conservadora alemana de 1918 a 1924, y particularmente en la controversia entre Schmitt y Koellreutter. Sin duda, hasta acá nuestra tesis reside en que el debate sobre la soberanía en Schmitt renuncia al totalitarismo como forma de poder legitima para Alemania, de allí la importancia no solo de la Constitución sino del defensor de la Constitución como único mecanismo para transformar el papel de Hitler en la Alemania de 1936 y garantizar con ello no solo la legitimidad jurídica y política del Reich, sino también la supervivencia de los valores morales constitutivos del Volk alemán (Mayorga, 2003, p. 121). En efecto, la temporalidad del caudillo está limitada por su duración física, por tanto, en cuanto encarna la Constitución y a pesar de su limitada temporalidad, esta no puede desaparecer con él, sino que muestra su supervivencia en su sentido sacro y temporal, en los valores constitutivos del pueblo mismo.

En este marco comprensivo, es posible entender la importancia del estado de excepción como condición política de la forma de la soberanía. Así, lo que se podrá decir por tanto es que la forma operativa misma de la decisión de la soberanía es el estado de excepción, librando al Estado de cualquier peligro republicanista liberal. En efecto, la situación alemana ante el vacío que generó la crisis política que a ojos de Schmitt se entrevé en la Constitución de Weimar, debido a la crisis de partidos, supone una situación extrema que conlleva necesariamente su necesidad para la supervivencia del Estado, que en sus palabras es resumido como: "extremus necessitatis casus" (Schmitt, 2004, p. 41). Por esto, Schmitt centra sus ataques en Kelsen y Preuß, por cuanto estos últimos son unos esperanzados creyentes en la vitalidad del texto constitucional per se y no en la encarnación del texto en la voluntad del soberano que lo defiende.

En el texto titulado Verfassungslehre, Schmitt centra la crítica política y constitucional en los principales exponentes del derecho positivo alemán: su crítica enfocada en Hans Kelsen podría condensarse en la dispersión de la decisión como factor detonante de la crisis de la Constitución, debido a la incapacidad del texto y la necesaria interpretación entre órganos fragmentados por grupos de individuos (Schmitt, 1970, p. 89). En este sentido, la crítica hecha por Schmitt a Kelsen encuentra un factor consonante con Hermann Heller en su obra Staatslehre, que a partir de la comprensión del derecho alemán trae consigo lo que Lucas Verdu anota como "el hundimiento de la democracia weimeriana". El hundimiento de un posible liberalismo alemán suponía de antemano la falta de cuidado respecto de las comprensiones de contexto referidas a las raíces históricas de la relación entre nación y Estado, así como la fragilidad de cohesión interna de este último, derivada de un concepto del individuo que se antepone como condición metafísica anterior al orden y a la sociedad. Y se hacía manifiesta, por ende, la debilidad de la condición autárquica del Estado como estatus colectivo (Heller, 2004, p. 121). Heller, si bien mantiene una distancia crítica con Treitschke, al proponer una lectura hegeliana del Estado en su texto publicado en 1921, Hegel und der nationale Machtstaatsgedanke in Deutschland. Ein Beitrag zur politisches Geisteisgeschichte, preserva una consonancia advertida en el párrafo anterior; esto es, la condición natural y cultural del Estado antes que la abstracción iusnatural. Para Heller, la condición de tiempo y lugar, además de la crítica de un biologicismo natural que equipara la asociación entre animales con la asociación entre los hombres es de base inadmisible por la implicación de la cultura como factor relevante de expresión humana. Adicionalmente, anota en su crítica a la inflexibilidad del derecho positivo de Kelsen y de Jellinek que la invariabilidad de la condición formal, propia de la condición jurídica del derecho positivo, señala un error de fondo en la comprensión del Estado, por cuanto no es la forma jurídica la que explica las condiciones de tiempo y lugar que se encuentran en la base de las asociaciones humanas, como lo explica en un concepto referido a la evolución histórica de la cultura como expresión del espíritu humano (Wissenssoziologie). Esto podría resumirse en una sentencia de interpretación: la Constitución no hace al Estado, sino que es el Estado el que se vale de una Constitución. Así, el Estado tiene una pretensión universal como evolución del espíritu, preservando su concordancia con el hegelianismo de las primeras décadas del siglo XX alemán.

La comprensión de este contexto, en el que los rozamientos teóricos entre posturas suponen una agudeza conceptual, muestra puntos secuenciales de encuentro, pero mantiene la pretensión y la distancia propias del 
intento de teorías generales como sistemas de pensamiento. Y es allí donde se ubica la comprensión del Estado en relación con la soberanía que va a desarrollar Carl Schmitt.

Lo anterior tiene un trasfondo de praxis empírica respecto de la teoría del Estado, y hacemos mención de la condición empírica en referencia directa a la condición histórica que va a gestar la revolución conservadora, que es el vórtice en el cual todo este conjunto de teorías confluye para tratar de dar una explicación a su presente, esto es, el fracaso de la Primera Guerra Mundial. Sin duda, es este evento el que marca la gramática de la teoría schmittiana sobre la soberanía y demarca su autenticidad teórica en medio de dicha confluencia de la posguerra que da origen a la República de Weimar, particularmente, porque se anota como principio positivo que es la Constitución sancionada en noviembre de 1919 el origen de un nuevo Reich alemán fundado en el derecho social (solizalesrecht) y la emergencia de una unidad de representación de los estados asociados bajo la figura de un presidente, aboliendo con ello la figura del káiser (Hardach, 1994, p. 264). Es muy importante anotar que la figura del káiser alemán nunca asumió esa condición representativa, función por la cual dicha figura es remplazada con la de un presidente. La figura del káiser en Alemania tuvo siempre una condición identitaria como forma cultural e histórica, factor que se hace palpable con el fracaso de la Constitución de 1849 y el rol de Federico Guillermo IV frente al liberalismo propuesto en la Constitución de Frankfurt. Sin embargo, tampoco asumió un absolutismo dinástico (Habsburgo) por sangre como el que intentó salvar Francisco José I en el Imperio austrohúngaro con ayuda del zar Nicolás I — que sin duda podría abrir paso a movimientos similares en Rusia-, quienes suprimieron los brotes liberales de la Revolución húngara por vía militar, terminando con los vaivenes republicanistas en Europa oriental con las ejecuciones del 6 de octubre de 1849. Así, frente a la condición empírica histórica sobre la Primera Guerra Mundial, que trae consigo nuevamente la incapacidad del republicanismo de mediados de siglo XIX ya mencionada, y que pareciese materializarse en el intento de la Constitución de Weimar, es dónde se va a enmarcar esta comprensión de la soberanía que bulle en el pensamiento de Schmitt y que tiene su trasfondo en la comprensión religiosa que se encuentra en su esencia (Hardach, 1994, p. 279).

La pregunta recurrente de los alemanes, intelectuales o de a pie, al comenzar la república instituida por la Constitución de Weimar, no versaba sobre el nuevo tiempo sustraído de la historia o eventos antecedentes, sino, muy por el contrario, sobre los mecanismos críticos propios del derecho en relación con las dos décadas precedentes a este proyecto republicano. (Preuß, 1889, pp. 177 y ss.). Las muchas preguntas parecen resumirse en algunos particulares como estos: ¿por qué Alemania perdió la Primera Guerra Mundial, si al parecer los resultados militares llevaban a un triunfo casi alcanzado eliminado el frente oriental en 1917?; ¿acaso no fue la determinación histórica de la nación alemana la que había alcanzado dicho triunfo sobre los proyectos liberales franceses, británicos y americanos?, o por el contrario, ¿fueron la aristocracia, los comunistas y algunos otros reductos de grupos sociales influyentes quienes habían traicionado la moral nacional y entregado al pueblo a su derrota por anteponer sus intereses sectarios y de clase a los fines históricos de la nación?

Estas preguntas se trastocarán en el argumento utilizado por el nacionalsocialismo para criticar las constituciones liberales, y que se ve reflejado en el discurso de Hitler sobre la democracia en 1937, al formular las tres preguntas que a su tenor mostraban la incapacidad de una democracia liberal, no solo para Alemania, sino para las sociedades occidentales: ¿quién fija la convicción de un pueblo?, ¿quién despeja y aclara al pueblo?, ¿quién educa a un pueblo? Sin duda, no son los partidos, porque ellos corresponden a las clases de la dirigencia tradicional y a las lógicas del capitalismo, contrarias a la nación, reduciendo la libertad histórica del pueblo a la libertad del mercado favorable a sus intereses de acumulación. Estos partidos, como extensión y herramienta de las élites políticas y económicas que para el nacionalsocialismo serán las mismas, conservan su fortaleza manteniendo al pueblo escindido de su horizonte de realización histórica, lo que según Hitler ya se había mostrado en la derrota de la guerra y mantenía su gramática jurídica en la Constitución de 1919. No sobra decir que estas mismas élites fueron la clave para el desarrollo y ascenso al poder del totalitarismo nazi, y de las que se establecerá una gruesa base social para mantener una armonización de 
la política económica en el Tercer Reich. Sin embargo, el punto hasta acá es mostrar que la ambivalencia discursiva sobre la materialidad histórica de la nación y una suerte de corporativismo emergen como respuesta a la crisis, que para los nacionalistas entre 1927 y 1933 fue leída como la traición de la aristocracia al pueblo alemán, y el último obstáculo puesto por el liberalismo bajo el sofisma de la democracia, para la realización histórica de la nación.

\section{Entre Leviathan y Beemoth: la paradoja europea}

Para los nacionalistas alemanes, la democracia liberal había llevado a fracturar la cohesión interna de la nación, y los movimientos liberales y comunistas alemanes habrían de ser los responsables de dicha fractura interna. Con ello, la subsecuente generación de un enemigo interno que hace naufragar las necesarias pretensiones continentales europeas alemanas de la primera década de siglo XX, por las que el Leviathan liberal había de derrotar al Behemoth figurado en el análisis de Franz Neumann (1968) sobre la confrontación a muerte que determinaría la condición de hegemonía mundial en manos del liberalismo democrático.

Este es el factor que logra vincular a Schmitt como un defensor del nacionalsocialismo desde una perspectiva un tanto institucionalista, esto es, poder estructurar una comprensión de la nación no particularmente pasional sino como una suerte de racionalidad que deviene constitucionalmente forma institucional (Schmitt, 1933 p. 29). Aquí sin duda se establecen las discusiones de fondo con Lowenstein y Koellreutter. En efecto, para Koellreutter, las construcciones políticas de Schmitt fundaban una teoría de la Constitución más que una teoría del Estado, que corría el riesgo de ser un modelo de Estado burgués de derecho no muy lejano a la concepción de Weimar sobre las dinámicas de la representación, los partidos y una ciudadanía fundada en la racionalidad del desarrollo del capitalismo liberal como sujeto-autonomía, lo que hacía imposible la consolidación de un Estado popular alemán. Los mismos argumentos de crítica usados por Koellreutter son usados en forma inversa por Lowenstein al decir que Schmitt renuncia a la apertura a una evolución histórica del derecho constitucional y de la teoría liberal del derecho como marco civilizatorio occidental.

En relación con este último, para Schmitt, las pretensiones de Loewenstein (1938, p. 731) - como eco kelseniano de un biologismo vacío de contenido histórico-, presuponían un rol de la Constitución en el que la adopción de los fundamentos democráticos se encontraría basada en una libertad natural que establecería una suerte de democracia, con su importancia en la validez del enfoque del empirismo anglosajón. Así, lo importante es el individuo como base de la comprensión orgánica del Estado, es decir, la forma empírica evolutiva del Leviatán hobbesiano. Contrariamente, la dogmática de Schmitt, destinada a demoler la tradición constitucional encaminada a sostener el positivismo jurídico, base fundamental de Weimar, evidencia por los resultados y la dinámicas sociales propias de la guerra, y por ende sus resultados, que fue este organicismo el que generó la fragmentación y la fractura interna de la sociedad alemana y por ende el responsable del fracaso nacional (Schmitt, 1974, p. 288).

En este punto Schmitt ya deja clara su comprensión estética de la Constitución. Asombra el entendimiento centrado en el poder soberano, puesto que concibe este como un factum. El poder soberano es por sí mismo válido, puesto que ni siquiera tiene pretensiones de ser validez, lo que establecería una condición de afuera al acto mismo de la decisión sobre la excepcionalidad como la condición política de la soberanía por excelencia (Schmitt, 2009b, p. 106). Para Schmitt, el poder soberano es un orden legitimado porque su unidad política es establecida través de la consolidación de un estatus colectivo, el cual es fortificado a través de una imagen de la sociedad como poder constituyente. Así, el poder constituyente está a todas luces referido, incluido en el acto mismo del poder soberano como factum. Esto último explica el que para Schmitt el fundamento del Estado se encuentre en la Constitución, tanto como zu sein - en cuanto ser-, y a su vez como zu sollen — referido al deber ser-. De esta manera, puede decirse que la realidad política define su misma validez, y 
por ende en el estado de excepción se manifiesta armónicamente la "existencia del Estado" y "su producción normativa", lo que permite la supervivencia duradera de aquel.

Si en Schmitt la soberanía se entiende como capacidad de decisión, se hace comprensible que el pueblo no pueda entenderse como una agregación de voluntades y libertades de tenor hobbesiano, puesto que incluso en su forma constituyente debe delegarse en su condición "inconstituida" a —esto porque el poder constituyente en sí mismo supone su inconstitución - una fuerza de "uno solo" que la ejerce y no que la representa; esto es, un individuo quien encarna la voluntad general y permite que el acto mismo de decidir tenga la suficiente fuerza y robustez que no tendría esta agregación de voluntades de tono contractual, debido a que toda forma de contrato diluye la fuerza misma de la decisión Schmitt, 2009a, p. 123). El pueblo jamás —en su forma constituyente- podrá estar presente como una sola identidad real si no se expresa en esa forma del poder soberano a través del defensor de la Constitución. Así, el pueblo no es el que toma las decisiones, sino el que hace depositario al líder de su fuerza moral constitutiva, siendo este el que al identificarse plenamente con él adquiere quien manifieste sus valores fundamentales. El soberano como defensor de la Constitución es aquel que guarda en sí la voluntad del pueblo, y la guarda en cuanto es idéntico a este, en cuanto encarna los valores populares reflejados en el trasegar histórico de una lectura concreta y colectiva en los elementos constitutivos de la sociedad.

Asumido esto, Schmitt evidencia que el soberano es quien ejerce la autoridad, y este es su punto de encuentro con Hobbes ${ }^{[21]}$, puesto que ambos consideran que el soberano, bien sea de forma representada o por identidad, es quien decide en relación con la vida y la muerte; y en ello reside el acto mismo de la soberanía como decisión sobre la excepción. En efecto, Schmitt en la primera y segunda edición de su teología política define claramente lo que logra entender por el soberano: "Soberano es aquel que decide sobre el estado de excepción" (Schmitt, 1985a, p. 35). En este orden de ideas, la comprensión del soberano como quien decide, solo puede ejercerse en cuanto la decisión acontece en la excepcionalidad misma, es decir: "La excepción es más interesante que el caso normal. Lo normal nada prueba; la excepción, lo prueba todo" (Schmitt, 1985b, p. 54). Por tanto, el uso racional del monopolio de la fuerza no resume la soberanía como la acción del soberano, sino la decisión misma es la que la define como el acto de decidir, en el cual se rompe cualquier orden normativo o producción legal formal. Ahora bien, la pregunta sobre el estado de excepción tiene su respuesta en la forma (Gestalt) de suspender el derecho, condición que determina su naturaleza soberana. Además, porque rompe cualquier externalidad al acto mismo de la decisión sobre este Estado.

¿Cómo entender al Beemoth? Sin duda, no podría existir otro referente para esta bestia terrestre que la tensión política de la relación amigo-enemigo, ello por cuanto esta relación no es dialéctica, luego, no tiene ninguna condición de negatividad productiva sino que nace de la posibilidad extrema de un combate real, de la posibilidad siempre presente de la guerra (entre Estados o entre grupos dentro de un mismo Estado), que constituye la situación extrema de la comprensión misma de lo político:

Los conceptos de amigo, enemigo y lucha adquieren su significado real por el hecho de que se refieren de modo específico a la posibilidad real de la exterminación física. La guerra deriva de la hostilidad puesto que ésta es negación absoluta de todo otro ser. La guerra es sólo la realización extrema de la hostilidad. No tiene necesidad de ser algo cotidiano o normal y ni siquiera de ser vista como algo ideal o deseable; debe, no obstante, existir como posibilidad real para que el concepto de enemigo pueda mantener su significado. Todo esto no quiere decir en absoluto, sin embargo, que la esencia de lo 'político' no sea otra cosa que la guerra sangrienta [...] La guerra no es pues ni un fin ni una meta, o tan sólo el contenido de la política, sino que es su presupuesto siempre presente como posibilidad real [...]. (Schmitt, 2009a, pp. 30-31)

Si bien para Schmitt la naturaleza de lo político no está dada por una comprensión de la guerra desde el sentimiento religioso - tema que no entraremos a discutir exegéticamente, puesto que algunos especialistas no conciben la guerra sino el conflicto en Hegel-, por lo que no es necesario que esta se produzca para que se manifieste lo político. La importancia de la guerra como condición sinónima de lo político radica en que constituye una posibilidad real y concreta de lucha, de matar o morir, con lo que se activa la decisión soberana sobre vida y muerte. 
En estos argumentos schmittianos reaparece la lectura del Leviatán de Hobbes. En efecto, para este último el estado de naturaleza se define como una situación de guerra de todos contra todos, donde

la guerra no consiste solamente en batallar, en el acto de luchar, sino que se da durante el lapso de tiempo en que la voluntad de luchar se manifiesta de modo suficiente [...] la naturaleza de la guerra consiste no ya en la lucha actual, sino en la disposición manifiesta a ella durante todo el tiempo en que no hay seguridad de lo contrario. (Hobbes, 1983, parte 1, cap. XIII, p. 136)

Es decir, mientras no haya un Leviatán que proteja a los individuos a cambio de su obediencia, o los mantenga a raya unos de otros en un pacto de individualidad con el soberano, la condición de la guerra natural será indefinida. Por tanto, la soberanía es la manera de dirigir y de encapsular la guerra como una forma (Gestalt) de lo político.

\section{A manera conclusiva: la legitimidad del Estado y el estado de excepción: el problema contemporáneo emergente de la memoria de la posguerra}

Al plantear la comprensión de Schmitt sobre el Estado y su identidad con lo político, es necesario advertir un punto de partida en la teoría del derecho del nacionalsocialismo, este es, que el punto de partida de cualquier teoría sobre lo político no puede estar centrado en el individuo, sino en la preservación y el fomento de la sociedad como una comunidad determinada por un condicionamiento histórico y racial que define una forma de "vivir" en sociedad para la realización de su propio destino, por ende, conlleva la recomprensión del derecho. Así, en el inicio de su concepto de lo político, Schmitt sitúa su crítica a Hans Kelsen estableciendo un ataque frontal al organicismo, factor que le permitirá definir de manera antitética su particular comprensión de "lo político". En este sentido, Schmitt afirma:

Wir dürfen es dahingestellt sein lassen, was der Staat seinem Wesen nach ist, eine Maschine oder ein Organismus, eine Person oder eine Einrichtung, eine Gesellschaft oder eine Gemeinschaft, ein Betrieb oder ein Bienenstock, oder vielleicht gar eine "Verfahrensgrundreihe". (Schmitt, 1985b) ${ }^{\text {[22] }}$

En este orden de ideas, y siguiendo a Hoffman (2010) en el texto Legitimität gegen Legalität: Der Weg der politischen philosophie Carl Schmitts, el problema de lo político para Schmitt en 1932 supone un existencialismo político con una profunda caracterización teológica, especialmente referida al decisionismo. Así, lo político y el Estado no están en relación ambigua uno respecto del otro, sino que por el contrario mantienen una relación identitaria en función de la decisión política. Esta comprensión sobre una suerte de decisionismo autoritario se observa claramente en la correspondencia que Schmitt entabla con Walter Benjamin, particularmente por intención de este último en torno al comentario sobre el drama barroco alemán. La carta comentada por Samuel Weber (1992) evidencia esta figuración sobre el decisionismo:

Sovereign is he who decides on the state of exception [Ausnahmezustand]. Only this definition can do justice to a borderline concept. Contrary to the imprecise terminology that is found in popular literature, a borderline concept is not a vague concept, but one pertaining to the outermost sphere. (p. 7)

Así, el Estado y lo político se encuentran propiamente en la decisión del soberano, de otra manera, el Estado es de suyo el "estado de excepción". De tal manera, la comprensión teológica en sus categorías subyacentes define en su base la relación amigo-enemigo, en cuanto es esta relación la que delinea aquella concebido por Schmitt como estado de excepción. Esta comprensión puede intuirse en el trabajo bajo el título legalidad y legitimidad. Anótese lo que el autor afirma:

There is no equality before the measure, as there is equality before the law. I can also not apply the law, impose sentences, or generally act authoritatively in the name of practicality, or factual necessity, or in the name of force of circumstances instead of in the name of law. (Weber, 1992, p. 11) 
De esta manera, la excepción está por encima de la ley misma y todo lo político está referido y contenido en el Estado. En esto se centra la principal crítica de Schmitt al modelo de la democracia liberal; ello porque lo que se denomina excepción (Ausnabmezustand) se concibe en oposición a un estado de normalidad (Normalzustand), siendo este último el que se ajusta a la aplicación de la ley (Kelsen, 1999, p. 53). Empero, para Schmitt lo excepcional es una constante o una característica del presente, lo que expone Verdú en referencia a la comparación entre el sistema jurídico-político de Schmitt y Kelsen: "El schmittiano se desenvuelve fuera de los cauces normativos, o por lo menos los relativiza a situaciones vitales, preferentemente las excepcionales" (Verdu, 1987, p. 71).

De esta manera, la comprensión de lo enemigo y lo amigo define la conceptualización misma de lo político, muy contraria a la comprensión de la soberanía y por ende del Estado enmarcada en la proposición hecha por Hugo Preuß. Acá la definición de lo político como la relación amigo-enemigo no se convierte en una oposición en cuanto comprensión dialéctica, particularmente porque no se concibe ningún tipo de negatividad en la comprensión misma de las fuerzas. Adicionalmente, en cuanto Schmitt no ve en esta oposición ninguna condición productiva en términos de síntesis. En este orden de ideas, paraSchmitt el Estado está desvinculado de lo gubernamental o gubernativo, por cuanto no es presa de la forma administrativa sino en su sentido específico en la relación propia de la oposición, no de armonización generalizada como lo percibe Preuß. En ello reside la crítica de Schmitt a Preuß, pero más particularmente puede comprenderse lo que Schmitt concibe en una relación a partir de dicha oposición. Preuß (1889) lo aclara a través de su cita de Martens:

Die Idee der Souveranitat involvirt nur das Eine, namlich dass jeder Staat fur sich eine selbstandige juristische Personlichkeit bildet; sie vermag jedoch nicht darüber Aufklarung zu geben, in welchen Beziehungen sich nun der eine Staat zum andern befindet. (p. 103)

Ahora bien, para Schmitt el concepto de lo político supone de suyo el estado de excepción. Insiste en que no es simplemente equivalente al uso lingüístico en alemán (Ausnabmezustand), entendido como una composición jurídica de un estado de sitio, puesto que de suyo no todo "peligro" o "amenaza" constituye una justificación de la suspensión de la norma según la comprensión misma del derecho liberal; esto porque termina siendo una contradicción a la producción legal misma. Así, Schmitt abandona la figura de la justificación de la amenaza para la comprensión de la excepción como lo propio al Estado político y se centra en que la excepción no puede ser la forma jurídica, sino el acto mismo de la decisión del soberana, es decir, la decisión es en su forma puramente política de la excepción, la cual define la existencia y supervivencia del Estado mismo.

De esta manera, el soberano es quien decide sobre el estado de excepción, y, por tanto, la comprensión del Estado a partir de la decisión misma conlleva dos momentos: primero, la decisión en la que de suyo existe un estado de excepción, y en segundo lugar, la suspensión efectiva del estado de derecho anteriormente vigente, por lo que el acto mismo de la soberanía al establecer la decisión determina efectivamente los límites del Estado. Y es este acto de delimitación lo que constituye la soberanía política según Schmitt o, en otras palabras, aquello que define la relación del Estado como Staat y la excepción como "estado" o Zustand. A este respecto Samuel Weber (1992) cita de Schmitt:

Always also something different [...] from an anarchy and a chaos, [and thus] order in the juristic sense still prevails even if it is not of the ordinary kind. The existence of the state is undoubted proof of its superiority over the validity of the legal norm. The decision frees itself from all normative ties and becomes in the true sense absolute. The state suspends the law in the exception on the basis of its right of self-preservation, as one says. (p. 10)

Y este mismo sentido lo expone Laclau (2007):

Schmitt, as we have seen, asserted that the function of the sovereign-in the state of exception-is to establish the coherence between law and the wider communitarian order (one cannot apply law to chaos). If this is so, however, and if the plurality 
of demands requires a constant process of legal transformation and revision, the state of emergency ceases to be exceptional and becomes an integral part of the political construction of the social bond. (p. 16)

Esta comprensión sobre la paradoja de Schmitt permite la de lo político y la del Estado. La paradoja o aporía de la posición de Schmitt se sugiere aquí porque si la "decisión" es tan radicalmente independiente de la norma como Schmitt afirma, es difícil ver cómo la decisión del Estado de suspender sus leyes puede justificarse en absoluto, ya que toda justificación implica precisamente el recurso a una norma. Esto no puede ser conceptualizado de otra forma, sino bajo la imagen de instinto de conservación: "El Estado suspende la ley en la excepción sobre la base de su derecho de autopreservación" (Verdu, 1987, p. 79), como fundamento permanente que engloba las imágenes del pasado en unicidad narrativa que hace legítima la concentración y autoridad directa del decisor.

En este orden de ideas, el Estado de excepción y en especial el dictador establecen un relato de la historia a través del cual se condensan las formas de la memoria. La excepcionalidad en su forma política establece un solo relato sobre la verdad que supera la forma jurídica y se establece como mecanismo de presente que legitima la acción política autoritaria. Renuncia a las formas de microhistorias o recursos de los invisibilizados y establece una historiografía con una teleología de los vencedores, que en toda forma siempre establece una necesidad de gobierno como condición salvífica del presente. Esta forma teológica hace que dicha estructura historiográfica defina una escatología permanente de la crisis, fruto de la memoria institucionalizada, que permitirá siempre y en todas sus formas la concentración del poder como mecanismo restaurador del caos. Esto, que evidencia Schmitt no solo en la forma del nacionalsocialismo, es la trampa recurrente en la que cae presa el liberalismo, por cuanto terminará siempre sobre la base de una agregación radical en la forma política que no tiene otro recurso que una historiografía teológico-secular que reafirme y renueve en forma permanente la imagen molar del poder soberano.

\section{Referencias}

Ata, A., y Şükrü, S. A. (2014). Talaat Pasha’s Murder (15.3.1921). A parody in the courts of Berlin belying "The Miller of Sansoucci legend of Justice". The International Journal of Social Sciences and Humanities, 1(5), 279-300. Recuperado el 22 de septiembre de 2017, de https://www.valleyinternational.net/thijsshi/v1-i5/1\%20theijssh i.pdf

Bendersky, J. W. (1983). Carl Schmitt. Theorist for the Reich. Princeton: Princeton University Press.

Bendersky, J. W. (1987). Carl Schmitt at Nuremberg. Telos, (72), 97-107.

Bendersky, J. (2007). "Panic": the impact of Le Bon's crowd psychology on U.S. military thought. The History of Behavioral Sciences Review, (3), 257-283.

Donoso Cortés, J. (1946). Obras completas (t. I). Madrid: Biblioteca de Autores Cristianos.

Durkheim, É. (1989). Alemania por encima de todo (La mentalidad alemana y la guerra). Revista Española de Investigación Sociológica, (45), 199-228. Recuperado de https://www.dialnet.unirioja.es/descarga/articulo/24 9748.pdf

Fichte, J. G. (1994). Discursos a la nación alemana. Barcelona: Altaya.

Hardach, G. (1994). La Primera Guerra Mundial 1914-1918. Barcelona: Folio.

Heller, H. (2004). Las ideas políticas contemporáneas. Granada: Editorial Comares.

Hobbes, T. (1983). El Leviatán. México: Fondo de Cultura Económica.

Hoffman, H. (2010). Legitimität gegen Legalität: Der Weg der politischen philosophie Carl Schmitts. Berlín: Duncker und Humbold Verlag.

Kelsen, H. (1999). Quién debe ser el defensor de la Constitución. Madrid: Tecnos.

Kolluta M. (2008). Deutsche verfassungsgeschichte. Vom Alten Reich bis Weimar (1495-1934). Berlín: Springer Verlag. 
Laclau, E. (2007). ¿Bare life or social indeterminacy? En G. Agamben (ed.), Sovereignty and life (pp. 11-22). Stanford: Stanford University Press.

Loewenstein, K. (1938). Legislative control of political extremism in European democracies II. Columbia Law Review, 38(5), 725-774. DOI: $10.2307 / 1116432$.

Maddock, R. (1986). Liberalismo económico e intervención estatal: ¿la mano o la pata invisible? Lecturas de Economía, (21), 34-58.

Mayorga, J. (2003). Revolución conservadora y conservación revolucionaria política y memoria en Walter Benjamin. Barcelona: Anthropos.

Meier, H. (1995). Carl Schmitt \& Leo Strauss: The hidden dialogue. Chicago: University of Chicago Press.

Meier, H. (2008). Carl Schmitt, Leo Strauss y el concepto de lo político. Un diálogo entre ausentes. Buenos Aires: Katz.

Neumann, F (1968). El cambio en la función de la ley en la sociedad moderna. En H. Marcuse (ed.), El Estado democrático y el Estado autoritario: ensayos sobre teoría política y legal. Buenos Aires: Paidós.

Preuß, H. (1889) Gemeinde, Staat, Reich als gebietskörperschaften. Versuch einer Deutsche staatskonstruktion auf grundlage der genossenschaftstheorie. Berlín: Springer Verlag.

Sarafian, A. (2011). Talaat Pasha's report on the Armenian genocide. Londres: Gomidas.

Schmitt, C. (1930). Staatsethik und pluralistischer Staat, Kant-Studien, Review, 35. Recuperado de https://www.me tabolicfoundation.nl/download/.../id=568696\&type=file

Schmitt, C. (1933). Staat, bewegung, volk. Die dreigliderung der politisiche einheit. Hamburgo: Hanseatische Verlag.

Schmitt, C. (1950). Ex captivitate salus: erfahrung der zeit 1945/47. Colonia: Sprengler Verlag.

Schmitt, C. (1969). Clausewitz como pensador político o el honor de Prusia. Revista de Estudios Políticos, (163), 5-30. Recuperado de https://www.dialnet.unirioja.es/descarga/articulo/2047034.pdf

Schmitt, C. (1970). Verfassungslehre. Berlín: Duncker \& Humblot.

Schmitt, C. (1974). Der Nomos der Erde im Völkerrecht des Jus Publicum Europaeum. Berlín: Duncker \& Humblot.

Schmitt, C. (1983). La defensa de la constitución. Estudio acerca de las diversas especies y posibilidades de salvaguardia de la Constitución. Madrid: Tecnos.

Schmitt, C. (1985a). La dictadura. Desde los comienzos del pensamiento moderno de la soberanía hasta la lucha de clases proletarias. Madrid: Alianza.

Schmitt, C. (1985b). Der Begriff des Politischen. Berlín: Springer Link Verlag.

Schmitt, C. (1996). The Leviathan in the state theory of Thomas Hobbes: meaning and failure of a political symbol. Connecticut: Greenwood Press.

Schmitt, C. (2004). Legality and legitimacy. Durham: Duke University Press.

Schmitt, C. (2009a). El concepto de lo político. Madrid: Alianza.

Schmitt, C. (2009b). Donoso Cortes in gesamteuropäischer interpretation: vier aufsätze. Berlín: Duncker\& Humboldt.

Schmitt, C. (2009c). La polémica Schmitt-Kelsen sobre la justicia constitucional "el defensor de la Constitución" versus “Quién debe ser el defensor de la Constitución?". Madrid: Tecnos.

Schmitt, C. (2010). Ex captivitate salus. Madrid: Trotta.

Schmitt, C. (2011). Catolicismo romano y forma política. Madrid: Tecnos.

Schmitt, C. (2014). The dictatorship: from the origin of the modern concept of sovereignty to proletarian class struggle. Londres: Polity Press.

Schulze Schneider, I. (1996). La Alemania de Bismarck. Madrid: Arco.

Steiner, R. (1989). Gesammelte Aufsätze Zur Kulturund Zeitgeschichte 1887-1901. Dürnau, Germany: Rudolf Steiner-Nachlaß Verwaltung. Retrieved from https://www.fvn-archiv.net/PDF/GA/GA031.pdf

Taubens, J. (1987). Jacob Taubens ad Carl Schmitt Gegenstrebige Fügung. Berlín: Merve Verlag. 
Verdu, L. (1987). La lucha contra el positivismo jurídico en la República de Weimar. La teoría constitucional de Rudolf Smend. Madrid: Trotta.

Waller, B. (1999). Bismarck. Barcelona: Ariel.

Weber, S. (1992). Taking exception to decision: Walter Benjamin and Carl Schmitt. Diacritics, 22(3/4), 5-18. Recuperado de https://www.jstor.org/stable/i219988

\section{Notas}

[1] Este tema está acuñado por Este tema es abordado por Rodney Maddock (1986).

[2] En 1988, la revista de izquierda Telos le dedicó un número especial a Carl Schmitt, y a raíz de aquel número se reabrió el debate sobre su obra y su persona en el mundo académico anglosajón. Una de las razones que se dieron para justificar la resurrección de Schmitt fue la supuesta falta de teoría del Estado en el seno del marxismo.

[3] Es importante revisar el informe elaborado por Pasha y publicado por Ara Sarafian (2011).

[4] A este respecto los investigadores Ata Atun y Şükrü Server Aya (2014, 281), afirman: "Talaat Pasha was living in Berlin in hideout, until he was traced by Nemesis and Soghomon Tehlerian was sent on duty to kill Talaat in revenge. Tehlerian made his way to Berlin, located the house of Talaat Pasha and shot him dead in the back on March 15, 1921 in front of his house. He was immediately caught by the people on the street and arrested by the police. Our story is intended to inform the reader about some of the details of this 'comedy of justice proceedings', given the fact that the German media seems to welcome all Armenian tales".

[5] Anótese el término de enemigo absoluto, que no tiene capacidad de elegir por cuanto no hay un juicio que lo establezca. Taubens (1987) afirma al respecto "Hitler nos ha determinado como enemigo absoluto" (p. 39).

[6] El interrogatorio fue publicado en el año de 1987 bajo el título "Carl Schmitt at Nuremberg".

[7] La edición revisada para este trabajo La edición revisada para este trabajo fue la de Schmitt (2010).

[8] "La Constitución podrá ser reformada por vía legislativa, pero para que prosperen las resoluciones del Reichstag modificativas de la Constitución se necesita que estén presentes dos tercios del número legal de sus miembros y que aprueben la medida dos tercios, por lo menos, de los presentes. Todos los acuerdos del Reichsrat para la reforma de la Constitución requerirán mayoría de dos tercios de los votos emitidos. Si por iniciativa popular hubiera de acordarse una reforma constitucional en referéndum, será necesario que la apruebe la mayoría de los electores con derecho a votar. Cuando el Reichstag vote una reforma constitucional frente al veto del Reichsrat, el presidente del Imperio no promulgará la ley si el Reichsrat solicita, en término de dos semanas, la celebración de un referéndum” (Art. 76).

[9] Véase carta de Walter Benjamin a Carl Schmitt, comentada por Weber (1992). Lo importante de este documento es su ocultamiento y posterior negación por parte de Max Horkheimer. Acá Benjamín expresa su admiración por Carl Schmitt y la importancia de su lectura de la excepcionalidad para interpretar el presente.

[10] Carta de Schmitt a Duschka Schmitt, citada por Bendersky. Véase también Schmitt (1950).

[11] Este registro de la biblioteca de Schmitt es inspirado por la relación que tiene este con Wilhem Frick y la redacción del Gutachten sobre el crimen en la declaración de guerras agresivas y ofensivas en el contexto del derecho internacional y el principio de Nullum crimen, nulla poena sine lege.

[12] Lo importante que tener en cuenta del texto es, como se sigue: "Der Führer schützt das Recht vor dem schlimmsten Mißbrauch, wenn er im Augenblick der Gefahr kraft seines Führertums als oberster Gerichtsherr unmittelbar Recht schafft: 'In dieser Stunde war ich verantwortlich für das Schicksal der Deutsche Nation und damit des Deutches Volkes oberster Gerichtsherr"' [El Führer protege el derecho de los peores abusos, cuando él en el instante de peligro, en virtud de su Führertums (dirección-como soberanía del líder), como juez supremo, inmediatamente crea derecho: 'En esta hora yo el responsable del destino de la Nación Alemana y con ello del Pueblo Alemán como Juez Supremo'”]. La traducción es del autor.

[13] Obsérvese la referencia en el prefacio a la edición en inglés en el que Carl Schmitt plantea realmente el problema de la dictadura: "The consequence of absolute 'technicity' 15 is an indifference that stands opposed to the further political purpose in the same way in which a technical engineer can have a purely technical interest in producing a thing without having any interest in its use; the thing produced does not need to be of any interest for him. Any political result - be it the absolute government of one single person or a democratic republic, the political power of a prince or the political freedom of the people - is just a task. The political organization of power and the technique for its maintenance and expansion differ according to the actual form of government. But the former always implies something that can be managed technically, just as the artist produces a piece of art according to his rational understanding. Depending on the concrete circumstances - geography, the character of the people, religious worldview, social power relations and traditions - the method differs and a different construction emerges" (Schmitt, 2014, p. 9).

[14] El texto al que se hace referencia es el de Schmitt (2011). 
[15] De igual forma se hace referencia a Schmitt (2009c).

[16] Es importante que a pesar de que Treitschke en su obra no hace referencia explícita a un soberano, bien se puede advertir su figura como superación histórica en el marco de la decisión. Esto lo explica bien Rudolf Steiner (1899): “Vor kurzem ist der zweite Band Treitschkes 'Politik' erschienen. Ein ehrlicher Bekenner des Monarchismus spricht sich über die Staatsformen aus. Drei mögliche Staatsbildungen unterscheidet er: die Theokratie, die Monarchie, die Republik. In der Theokratie fußt die oberste Staatsgewalt auf dem Glauben, dass sie von den göttlichen Mächten eingesetzt ist und in ihrem Namen regiert". (p. 35)

[17] La referencia de cita de este texto se hace en la traducción hecha al español publicada por la Revista Española de Investigación Sociológica número 45, a pesar de que su publicación original fue en 1915 bajo el título Deutschland über alles.

[18] "Des Weiteren trafen sich gemäßigte Liberale vornehmlich aus Südwest- und Westdeutschland am 10. Oktober 1847 in Heppenheim [...] Freiheitsforderungen, rechtsstaatliche Grundsätze und ein gemäßigtes sozialpolitisches Programm (namentlich die Grundlastenablösung) bildeten weitere Gegenstände dieses als 'Heppenheimer Programm' bekannt gewordenen Versammlungsprotokolls. Gemeinsam war Offenburger wie Heppenheimer Programm der Gedanke, dass der Nationalstaat nicht das Werk der deutschen Regierungen, sondern der gesamten deutschen Nation sein müsse”.

[19] El poder de Alemania y Bismarck se plasma a través de los sistemas bismarckianos, que se definen como el conjunto de alianzas internacionales patrocinadas por Bismarck, que se desarrollaron entre 1870 y 1890 . Los objetivos de este sistema de alianzas eran aislar a Francia, el gran enemigo de Alemania en el continente (derrota guerra franco-prusiana, cuestión de Alsacia y Lorena, intereses contrapuestos), potenciar el papel de Alemania como juez de la política internacional, asegurar el equilibrio y la paz (Realpolitik de Bismarck). Primer sistema (1871-1878): formado por la entente de los tres emperadores (Alemania, Austria-Hungría y Rusia), es una unión militar de carácter defensivo. Se disuelve en 1878 por las disputas ente Austria-Hungría y Rusia tras el Congreso de Berlín que hacia un reparto de los Balcanes. Segundo sistema (1879-1887): formado por tres alianzas: (1) dúplice alianza (Alemania y Austria-Hungría); (2) acuerdo austro-germanoruso; (3) triple alianza (Alemania, Austria, Italia). Este sistema fracasa también por los problemas en los Balcanes. Tercer sistema (1887-1890): formado por tres alianzas: (1) renovación Triple Alianza; (2) Acuerdo de Reaseguro (Alemania y Rusia); (3) Acuerdo del Mediterráneo (Gran Bretaña, Italia, Austria-Hungría y España).

[20] Nótese el concepto de estatus por antonomasia que usa Schmitt en el concepto de lo político.

[21] Es importante tener en cuenta que este debate lo va a retomar Schmitt en su texto Staatsethik und pluralistischer Staat (1930, p. 36).

[22] La traducción es propia: “Tenemos que dejar abierta la cuestión de cuál es el Estado en su esencia, una máquina o un organismo, una persona o una institución (dispositivo), una sociedad o una comunidad, una empresa o una colmena, o tal vez incluso una 'serie de procedimiento'”.

* Artículo de reflexión

\section{Licencia Creative Commons CC BY 4.0}

Cómo citar este artículo: Vega Díaz, L. F., y Avella de Martínez, D. I. (2018). La memoria y la forma política: una lectura de Carl Schmitt sobre la soberanía y el estado de excepción. Papel Político, 23(2). 1-16. https://doi.o rg/10.11144/Javeriana.papo23-2.mfpl 